\title{
MAHLI on Mars: lessons learned operating a geoscience camera on a landed payload robotic arm
}

\author{
R. Aileen Yingst ${ }^{1}$, Kenneth S. Edgett ${ }^{2}$, Megan R. Kennedy ${ }^{2}$, Gillian M. Krezoski ${ }^{2}$, Marie J. McBride ${ }^{2, a}$, \\ Michelle E. Minitti ${ }^{1}$, Michael A. Ravine ${ }^{2}$, and Rebecca M. E. Williams ${ }^{1}$ \\ ${ }^{1}$ Planetary Science Institute, Tucson, Arizona, USA \\ ${ }^{2}$ Malin Space Science Systems, San Diego, California, USA \\ anow at: Purdue University, West Lafayette, Indiana, USA \\ Correspondence to: R. Aileen Yingst (yingst@psi.edu)
}

Received: 18 December 2015 - Published in Geosci. Instrum. Method. Data Syst. Discuss.: 10 March 2016

Revised: 12 May 2016 - Accepted: 22 May 2016 - Published: 10 June 2016

\begin{abstract}
The Mars Hand Lens Imager (MAHLI) is a 2-megapixel, color camera with resolution as high as $13.9 \mu \mathrm{mpixel}^{-1}$. MAHLI has operated successfully on the Martian surface for over 1150 Martian days (sols) aboard the Mars Science Laboratory (MSL) rover, Curiosity. During that time MAHLI acquired images to support science and science-enabling activities, including rock and outcrop textural analysis; sand characterization to further the understanding of global sand properties and processes; support of other instrument observations; sample extraction site documentation; range-finding for arm and instrument placement; rover hardware and instrument monitoring and safety; terrain assessment; landscape geomorphology; and support of rover robotic arm commissioning. Operation of the instrument has demonstrated that imaging fully illuminated, dust-free targets yields the best results, with complementary information obtained from shadowed images. The light-emitting diodes (LEDs) allow satisfactory night imaging but do not improve daytime shadowed imaging. MAHLI's combination of finescale, science-driven resolution, RGB color, the ability to focus over a large range of distances, and relatively large field of view (FOV), have maximized the return of science and science-enabling observations given the MSL mission architecture and constraints.
\end{abstract}

\section{Introduction}

Operating more than 1150 sols on the Martian surface, the Mars Hand Lens Imager (MAHLI), aboard the Mars Sci- ence Laboratory (MSL) Curiosity rover, has been used by the MSL Science Team to interrogate geologic targets at the millimeter to sub-millimeter scale (individual grains and grain relationships). The goal of the MAHLI science investigation is to identify and interpret lithologic and textural clues that reveal processes responsible for forming and modifying the geologic record at the rover's field site in Gale crater (Edgett et al., 2012). We present here a brief overview of the MAHLI investigation activities and results from the first 1150 sols, and the key lessons learned in operating this instrument.

\section{Instrument}

MAHLI is a 2-megapixel, color camera with a macro lens that is able to focus on targets at working distances from $2.1 \mathrm{~cm}$ to infinity (Edgett et al., 2012; working distance is measured from the camera lens to the target). The camera head is mounted on a rotatable turret at the end of Curiosity's robotic arm (Fig. 1; Anderson et al., 2012). The arm positions the camera, allowing MAHLI to image targets from a wide variety of perspectives both around and on the rover. Two contact sensor probes extend $1.9 \mathrm{~cm}$ from the front lens element to prevent the lens from contacting the surface (Anderson et al., 2012). MAHLI was designed to provide data salient to understanding the stratigraphy, grain-scale texture, structure, mineralogy, and morphology of geologic targets.

Textures imaged by MAHLI mimic those resolvable by a geologist's hand lens. When contrasting with surrounding materials, at its highest resolution (14-18 $\mathrm{mm} \mathrm{pixel}^{-1}$ ), MAHLI can resolve individual grains down to coarse silt 


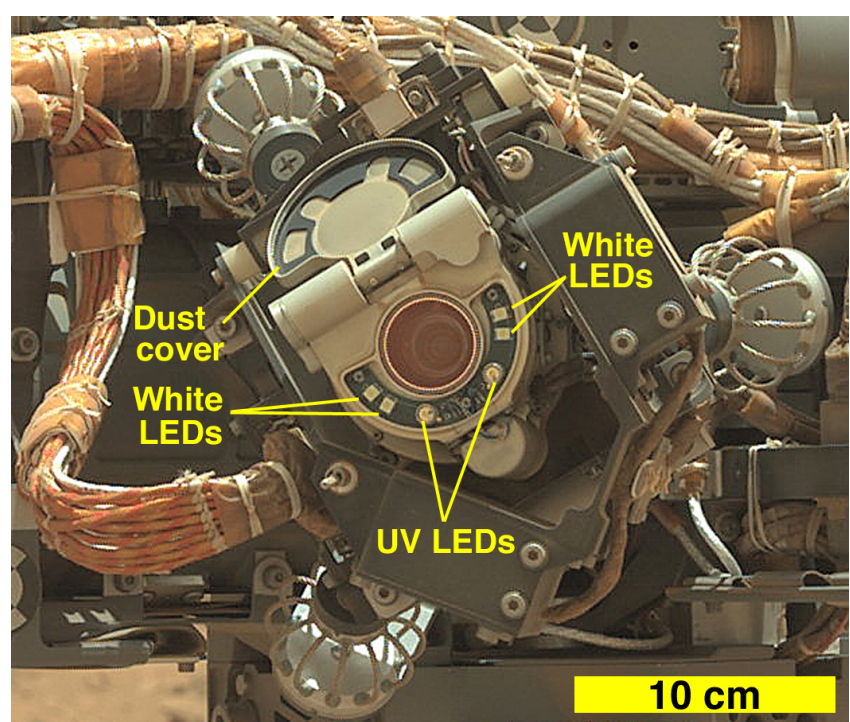

Figure 1. MAHLI camera head with dust cover open, as seen on Mars by Curiosity's left mast camera (Mastcam-34) on sol 84, 31 October 2012 (portion of image 0084ML0003740000102846E01).

size (Edgett et al., 2015). More typically for Mars, where differences between materials are more subtle, MAHLI images can permit distinction of very fine sand from silt (silt grain sizes as defined by Wentworth, 1922, $>62.5 \mu \mathrm{m}$ diameter) from unresolvable coarse silt-sized or smaller. This is particularly important to the MSL goal of detecting environments that may once have been habitable (Grotzinger et al., 2012), as mudstone is a great preserver of biosignatures (e.g., Summons et al., 2011).

The instrument also includes four white light and two ultraviolet $(365 \mathrm{~nm})$ light-emitting diodes (LEDs) to illuminate targets when warranted. White light LED pairs can be commanded together or separately so targets can be illuminated from multiple directions. MAHLI onboard data processing includes a focus merge (z-stacking) capability and lossless and lossy data compression options. Comprehensive details on the design and operation of MAHLI are in Edgett et al. (2015).

\section{Summary of MAHLI activities}

During its Primary Mission (August 2012-September 2014), Curiosity operated on Aeolis Palus, a lowland in northern Gale between the crater's north wall and a $5 \mathrm{~km}$ high mountain of stratified rock, Aeolis Mons (known informally as Mt. Sharp). Since September 2014, the rover team has been investigating rocks exposed on the lowermost northern flank of Aeolis Mons. The area explored consists largely of thinly mantled to bare outcrops of wind-eroded clastic sedimentary rock. Many of these were mafic fluvial sandstones and conglomerates, while others were siltstones and mudstones
(Williams et al., 2013; Grotzinger et al., 2013, 2015). Eolian bedforms, usually of centimeters to decimeters height, were also encountered. Examples of images of geologic targets acquired by MAHLI, over a range of scales, are shown in Figs. 2-5.

Typical MAHLI images of rock, regolith, and eolian targets included color images, focus stacks, and stereo pairs. The first science-driven imaging sequence on a rock target was designed to provide context for higher-resolution images $\left(100 \mu \mathrm{mpixel}^{-1}\right)$, data at scales comparable to the Mars Exploration Rovers (MER) Microscopic Imagers (MI; $31 \mu \mathrm{mpixel}^{-1}$ ), and highest-resolution images (16$22 \mu$ pixel $^{-1}$ ). Each of these resolutions required a different position of the robotic arm (stand-off distance). An additional image at $31 \mu \mathrm{m}$ pixel $^{-1}$ ( $5 \mathrm{~cm}$ distance) was also acquired at a slight offset from the first to provide stereo; this resolution was chosen for stereo pairs because it was close enough to resolve microtexture, but far enough away to be considered less risky to attempt - in terms of hardware collision with geologic material - than a closest approach (and thus best resolution) would be. Because every imaging sequence must be vetted multiple times, each change in an imaging sequence adds complexity and thus significant time to the planning cycle. As a result, this grouping of three resolutions quickly became the typical observational sequence used when acquiring images of science targets. These image stand-off distances were chosen early in the mission, but their usefulness has led to their being retained largely unchanged up to the present time. This "standard" sequence (without the extra stereo image) is shown in Fig. 3.

The images and other vital science and science-enabling observations enabled by the field of view and focus of the camera include

1. grain-scale rock textural analysis (e.g., grain size, shape, rounding, voids) that contributed to interpretations of rock type, facies, and diagenetic conditions (e.g., Grotzinger et al., 2013, 2015; Stack et al., 2014) (Figs. 2-3);

2. examination of eolian sand deposits, which informed a global understanding of fundamental properties and processes of eolian transport and bedform stabilization when compared to similar features at other Mars rover sites (e.g., Minitti et al., 2013; Sullivan et al., 2014; Fig. 4);

3. images for the robotic arm engineers to make lateral adjustments, based on a contextual-resolution MAHLI image acquired on a prior sol (Minitti et al., 2013), and quantitative measurements to support placement of the rover's Alpha-Proton X-ray Spectrometer (APXS), drill and scoop (Fig. 5; Robinson et al., 2013);

4. sample extraction site documentation, including rover self-portraits to provide context (Fig. 2); 

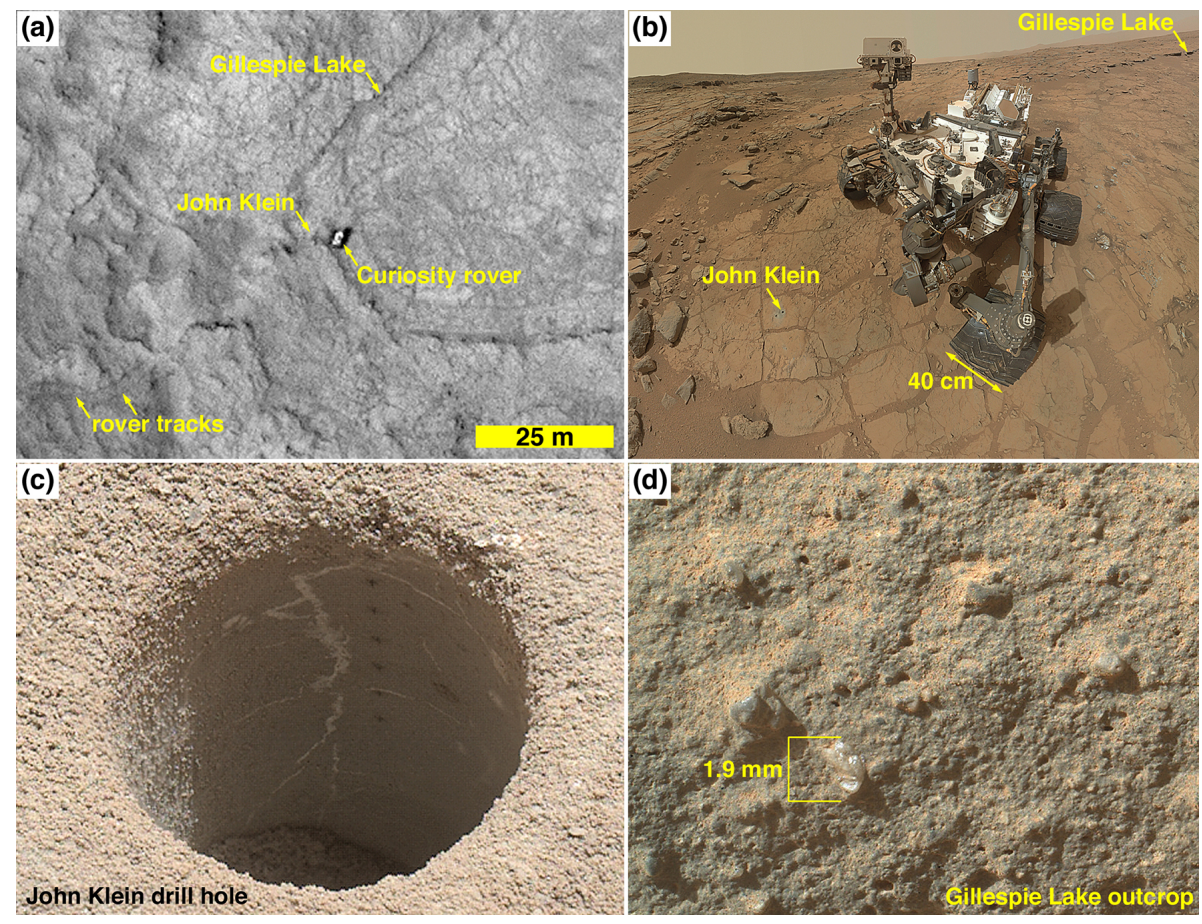

Figure 2. MAHLI is designed to be able to provide a combination of a relatively large field of view (ideal for mosaics, landscape views, and hardware inspection) and high spatial resolution (for geologic investigation), allowing the camera to be used to acquire images that connect grain-scale views to landscape- and regional-scale views. (a) Mars Reconnaissance Orbiter (MRO) High Resolution Imaging Experiment (HiRISE) orbiter camera view of Curiosity's Yellowknife Bay field site, with the Gillespie Lake outcrop and John Klein sample extraction (drill hole) sites indicated. Illuminated by sunlight from the lower left, this is a portion of HiRISE image ESP_030313_1755; it shows the rover position on sol 156 (13 January 2013). (b) Mosaic of MAHLI images acquired on sols 177 (3 February 2013) and 270 (10 May 2013) showing locations of the Gillespie Lake outcrop and John Klein drill hole with the Curiosity rover for scale; this view is illuminated by sunlight from the left. (c) Oblique close-up view of the John Klein sample extraction hole that was drilled into light gray Sheepbed mudstone on sol 182 (9 February 2013). This view shows mineralized veins (white) and a vertical row of spots created by Curiosity's ChemCam laser. The hole diameter is $16 \mathrm{~mm}$ and sunlight illuminated the scene from the upper right; this is a portion of a focal plane merge product created on Earth after radiometric calibration of eight consecutively acquired sol 270 (10 May 2013) MAHLI images, 0270MH0002540050102792C00 through 0270MH0002540050102799C00. (d) Close-up view of the Gillespie Lake sandstone. Illuminated by sunlight from the upper left, this is a portion of MAHLI focus merge product 0132MH0001630000101282R00 created onboard the instrument from eight images acquired on sol 132 (19 December 2012).

5. imaging of rover wheels to assess and monitor damage (Fig. 6), as routine imaging of the wheels relatively early in the mission revealed a much larger number of damage points than had been previously seen over a similar distance (Vasavada et al., 2014; Yingst et al., 2014);

6. consistent documentation of APXS analysis spots to support interpretation of geochemical data across multiple rover sites (Fig. 7);

7. imaging in support of robotic arm operation and the second phase of rover commissioning during sols 32-37, to validate the behavior of the arm under Martian conditions (Fig. 8; Robinson et al., 2013);

8. observations of landscape geomorphology (Fig. 9) and airborne dust;
9. imaging of other instrument hardware (e.g., the APXS calibration target, the CheMin inlet funnel, the Sample Analysis at Mars (SAM) tunable laser spectrometer (TLS), the Rover Environmental Monitoring System (REMS) ultraviolet (UV) sensor and the ChemCam remote warm electronics box (RWEB)) to support their safety and health (Blake et al., 2013; Edgett et al., 2012; Gómez-Elvira et al., 2012; Wiens et al., 2012; Campbell et al., 2014; Figs. 10-12); and

10. observations of the properties and configuration of eolian dust that settled on natural and rover hardware surfaces (Fig. 12). 


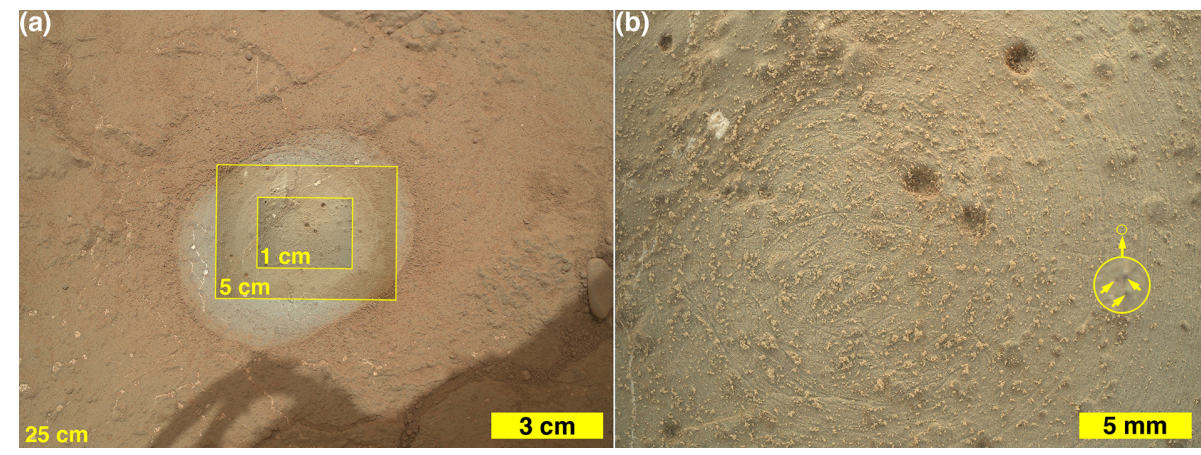

Figure 3. Sheepbed mudstone target, Wernecke, and example of nested MAHLI image acquisitions of increasing spatial resolution. (a) The three MAHLI images were acquired on sol 169 (26 January 2013) at working distances of 25, 5, and $1 \mathrm{~cm}$ (indicated), yielding images at $\sim 100, \sim 31$, and $\sim 17 \mu \mathrm{m}$ per pixel, respectively. This is a composite of image 0169MH0002050010102201C00 and focus merge products 0169MH0001630000102236R00 and 0169MH0001630000102232R00. (b) View of Wernecke from $1 \mathrm{~cm} \mathrm{standoff}\left(16.6 \mu \mathrm{m} \mathrm{pixel}^{-1}\right)$ in focus merge product $0169 \mathrm{MH} 0001630000102232 \mathrm{R} 00$. Arrows inside circular inset point to dark gray grains in the rock. Because of their contrast relative to the bulk, lighter gray matrix, the darker grains provide a constraint on the mudstone particle size; they can be no larger than $\sim 34 \mu \mathrm{m}$ and no smaller than $\sim 17 \mu \mathrm{m}$.

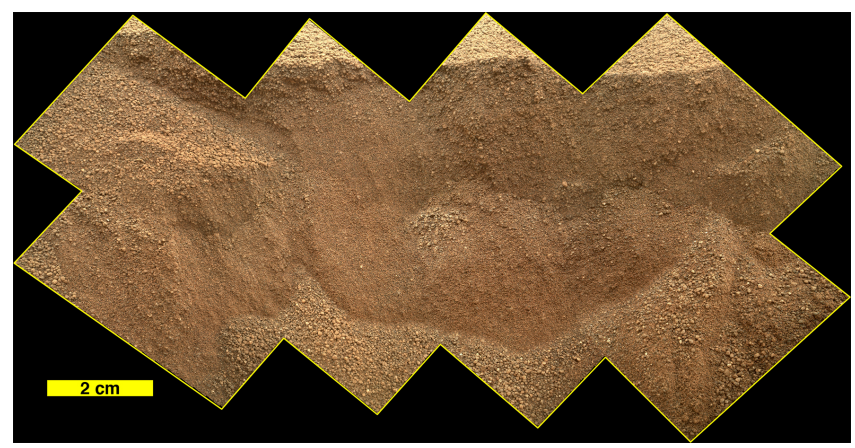

Figure 4. Mosaic of MAHLI focus merge products - composed of images acquired on sol 802 (8 November 2014) - covering a surface cut by scuffing Curiosity's right front wheel into an eolian bedform on sol 799 (5 November 2014). Illuminated by the Sun from the top/left (thus the wheel scuff wall is in shadow), this is a composite of focus merge products 0802MH0004400000300440R00, 0802MH0004400000300442R00, 0802MH0004400000300444R00, 0802MH0004400000300446R00, 0802MH0004400000300448R00, 0802MH0004400000300450R00, 0802MH0004400000300452R00, and 0802MH0004400000300456R00.

\section{Image scale and range finding}

MAHLI image scale, for targets at working distances of 2.1$210 \mathrm{~cm}$, is related directly to the instrument's stepper motor count. This relationship was empirically determined by measuring features of known scale, at known distance, on both Earth and Mars (Edgett et al., 2015). When the dust cover is open (which is the nominal operation mode on Mars because the dust cover was coated with a film of dust during the rover's terminal descent), the relationship between motor count $\left(m_{\text {open }}\right)$ and working distance $(w$, in $\mathrm{cm})$ is expressed

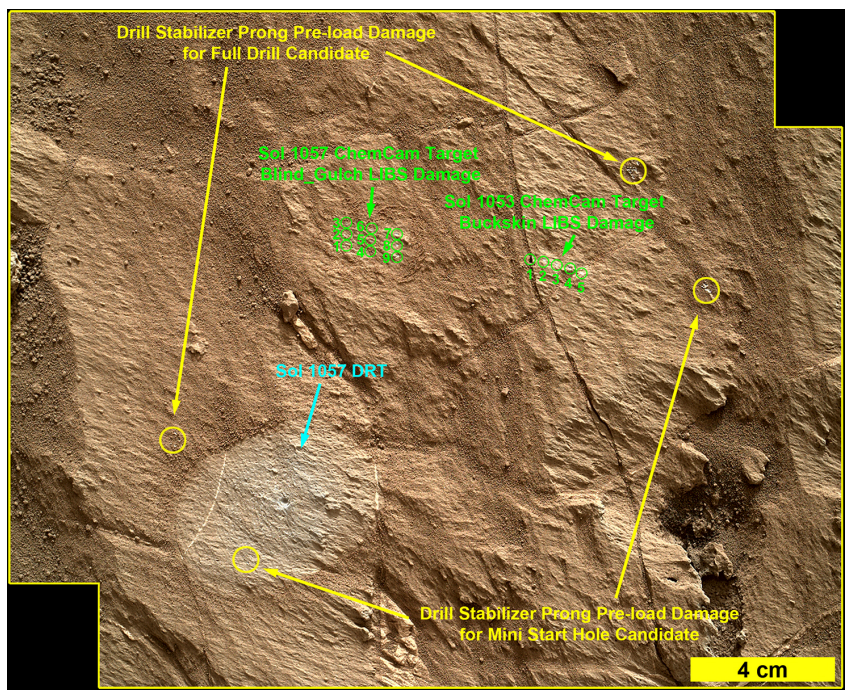

Figure 5. MAHLI image mosaic documenting the planning effort for placement of drill hardware, acquired on sol 1057 (28 July 2015) in preparation for drilling the rover team's Buckskin drill target. Such imaging for drill activity planning is commonly acquired at $35 \mathrm{~cm}$ distance for accurate placement of the drill stabilizers and drill, and for confirmation that drill activities were executed nominally and results were as expected. In this diagram, LIBS Damage refers to surfaces destructively investigated using the rover's ChemCam Laser-Induced Breakdown Spectrometer; DRT refers to a spot swept clean of dust by the rover's Dust Removal Tool; Blind_Gultch and Buckskin are names assigned by the team to the geologic targets investigated. Illuminated by sunlight from the top, this is a composite of images 1057MH0004240010400357C00 and 1057MH0004240010400359C00.

as follows:

$w=\left(a m_{\mathrm{open}}^{-1}+b+c m_{\mathrm{open}}+d m_{\mathrm{open}}^{2}+e m_{\mathrm{open}}^{3}\right)^{-1}$ 


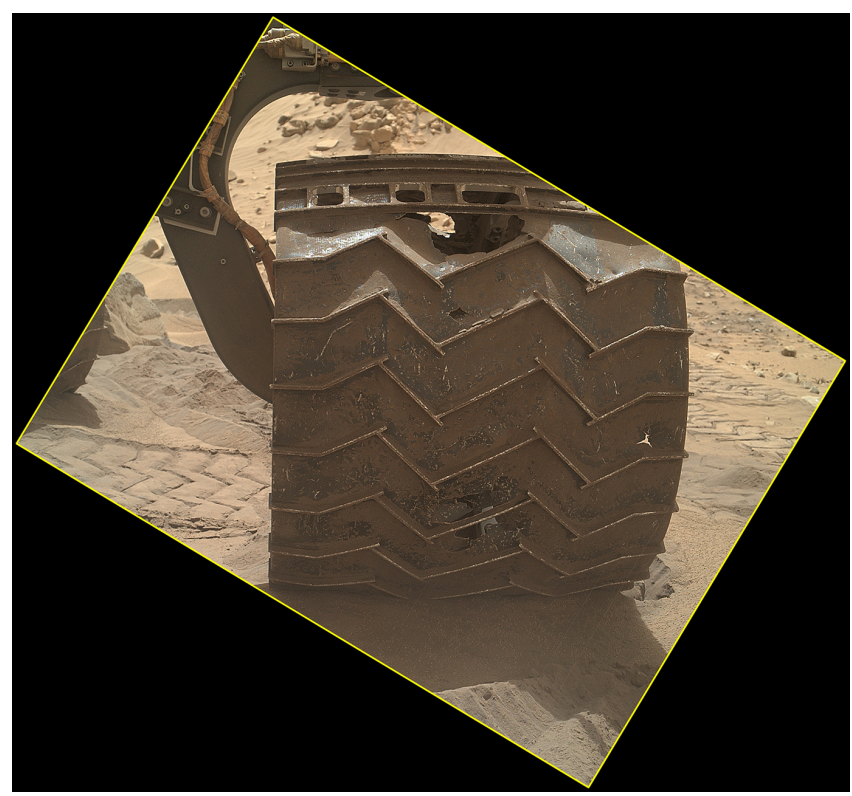

Figure 6. Example of rover wheel inspection imaging, acquired on sol 713 (8 August 2014). Curiosity's wheels are $40 \mathrm{~cm}$ wide. Because the wheels are a non-renewable resource, MAHLI is used on a regular basis to monitor damage; thus, single MAHLI wheel imaging (SMWI) is acquired after every $\sim 100 \mathrm{~m}$ of driving and full MAHLI wheel imaging (FMWI) is acquired every $\sim 500 \mathrm{~m}$. MAHLI images also contribute to the science team's efforts to identify and avoid driving across terrain that is potentially hazardous to the wheels (Yingst et al., 2014). Illuminated by sunlight from the upper left, this is MAHLI image 0713MH0002620000204354E01.

in which $a=0.576786, b=-11.8479, c=2.80153 \times 10^{-3}$, $d=-2.266488 \times 10^{-7}$, and $e=6.26666 \times 10^{-12}$.

When the camera is focused with the dust cover open, over the 2.1 to $210 \mathrm{~cm}$ range, the relationship between the motor, the relation between working distance $(w$, in $\mathrm{cm})$ and the width of the area covered by each MAHLI square pixel ( $p$, in $\mu \mathrm{m}$ ), assuming the target is in focus and is a plane parallel to the camera's $\mathrm{CCD}$, is

$p=6.9001+3.5201 w$.

Equations (1) and (2), used together, determine the pixel scale of any given image acquired by MAHLI at working distances from 2.1 to $210 \mathrm{~cm}$. Equation (1) can also be used to determine the distance of the camera, and thus the robotic arm, from a target imaged by MAHLI (range finding). This capability supports precise and repeatable placement of the robotic arm, and was employed to place the robotic arm scoop for sampling of the Rocknest sand shadow eolian feature on sols 60-89 (Minitti et al., 2013). Depth of field (DOF) contributes to uncertainty in the relation between working distance, motor count, and pixel scale. Depth of field $\left(d_{\text {near }}\right.$ and $d_{\text {far }}$ ) increases with increasing working distance, and is

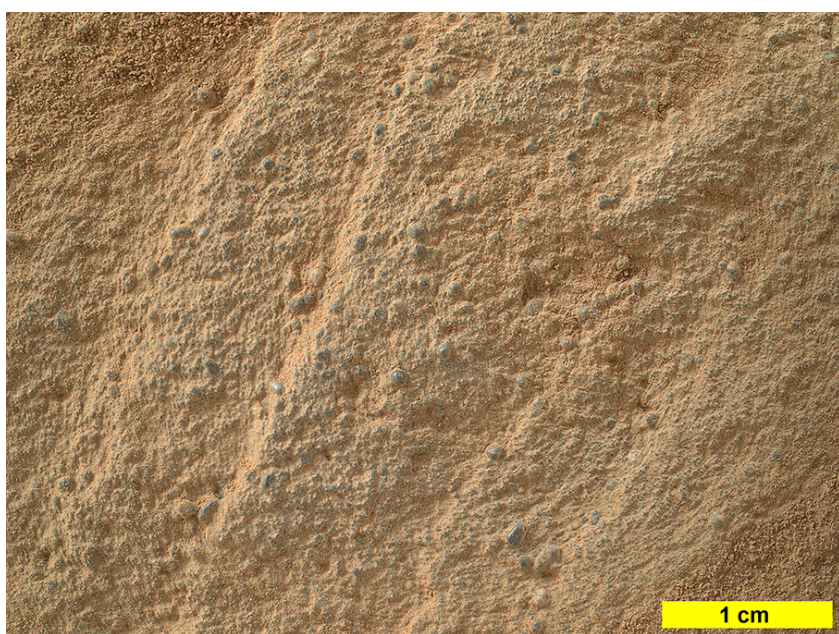

Figure 7. MAHLI view of a sandstone target named Ledger, acquired on sol 1092 (2 September 2015) after brushing, documenting the spot at which the APXS collected geochemical data. MAHLI acquires images from $\sim 7 \mathrm{~cm}$ working distance (field of view $\sim 5 \times 3.75 \mathrm{~cm}$ ) at most APXS science targets; this documentation is possible because the offset between the center of a MAHLI image and the center of an APXS integration spot is $0.5-5 \mathrm{~mm}$ despite the instruments being positioned on opposite sides of the robotic arm turret (VanBommel et al., 2015). Image documentation has proven to be crucial in assessing the amount of dust cover influencing the chemistry of APXS integration. On targets where dust has been largely cleared away by the Dust Removal Tool (DRT), MAHLI images record grains, veins, fractures and remnant dust that may contribute the measured APXS chemistry. This figure shows Ledger shadowed by rover hardware (sunlight is otherwise from the upper left); this is onboard focus merge product 1092MH0001700000401024R00.

determined by

$d_{\text {near }}$ or $d_{\text {far }}=\left(a m_{\text {open }}^{-1}+b+\mathrm{cm}_{\text {open }}+d m_{\text {open }}^{2}+e m_{\text {open }}^{3}\right)^{-1}$,

in which, for $d_{\text {near }}, a=1.03565, \quad b=-11.9083$, $c=2.82403 \times 10^{-3}, \quad d=-2.29003 \times 10^{-7}, \quad$ and $e=6.34332 \times 10^{-12}$, and, for $d_{\text {far }}, a=1.03438$, $b=-11.4118, c=2.69297 \times 10^{-3}, d=-2.17752 \times 10^{-7}$, and $e=6.02494 \times 10^{-12}$ (Edgett et al., 2015).

\section{Data distribution}

MAHLI data and data products are archived with the NASA Planetary Data System (PDS) according to a release schedule determined by the MSL Project and NASA PDS. As of 16 March 2016, all data received as of sol 1159 (9 November 2015) have been validated and archived; this includes all MAHLI images acquired during interplanetary cruise and pre-launch testing. In addition to the NASA PDS archives, all MAHLI images from Mars are placed online, typically less than $1 \mathrm{~h}$ after receipt on Earth, on a public website main- 


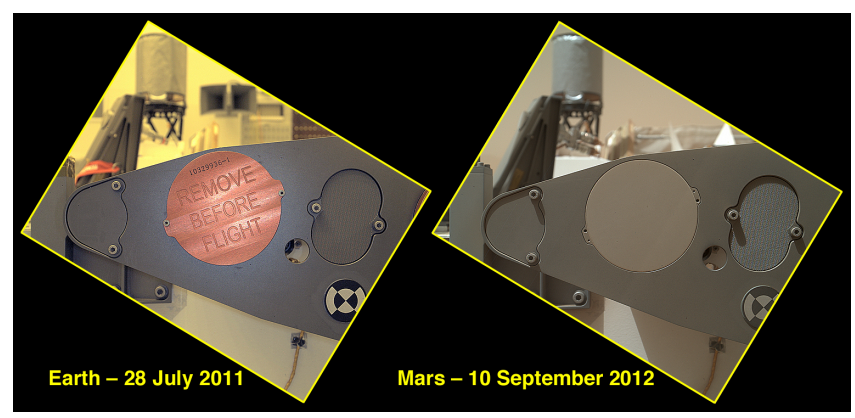

Figure 8. Example of MSL MAHLI imaging support for robotic arm teach point establishment. The front end of the Organic Check Material-1 canister (OCM-1; circular feature) diameter is $6.25 \mathrm{~cm}$ (Conrad et al., 2012). During the second phase of rover commissioning (sols 32-37; 8-13 September 2012), MAHLI was employed to image (1) portions of the rover to record their postlanding status, and (2) pre-launch-designated arm and turret positions (teach points) at rover hardware positions that were expected to be imaged repeatedly over the course of the mission. These included two of the five OCMs (1 and 5; Conrad et al., 2012), one of two replacement drill bit boxes (Anderson et al., 2012), and the observation tray (Anderson et al., 2012, Berger et al., 2014). In this example, OCM-1 was imaged before launch in July 2011 (left; image ATL_MH0090060020001340E01, illuminated by artificial overhead lighting and MAHLI's white light LEDs) and then imaged again on Mars in September 2012 (right; image 0034MH0000410010100009C00, illuminated by sunlight from the top left).

tained by the MSL Project at the California Institute of Technology's Jet Propulsion Laboratory. For this rapid, immediate image release effort, MAHLI images that arrive on Earth as JPEG-compressed products are placed online exactly as received from Mars; for data received with lossless or no compression, the data are color-interpolated, saved as a JPEG with compression quality $95 / 100$, and then placed online; these practices ensure the public immediately receives the highest quality JPEGs.

\section{Lessons learned during operations}

MAHLI has performed nominally on Mars. Here we discuss the lessons learned through 1150 sols of operation, or approximately 3 Earth years.

\subsection{Operations lessons learned}

\subsubsection{Use limitations}

After a major scientific campaign exploring the lacustrine rock record at Yellowknife Bay (Grotzinger et al., 2013), Curiosity's primary goal was to reach the geological targets on Aeolis Mons (Mt. Sharp; Grotzinger et al., 2012). This focus on driving limited the nature and extent of all science observations during the during the July 2013-September 2014 tra-

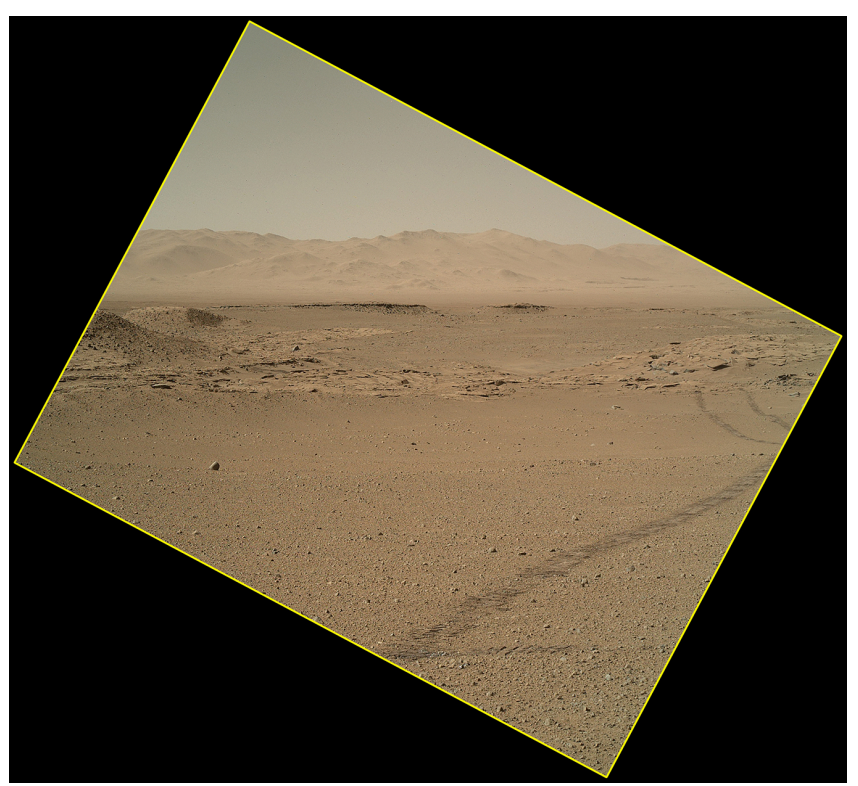

Figure 9. Example of MAHLI's view of the landscape acquired on sol 634 (19 May 2014) when the robotic arm was in a stowed position. This view, looking toward the north wall of Gale crater (background), shows the Kimberley field site and Windjana drill location (left). The outer-edge distance between the right and left wheel tracks is about $2.8 \mathrm{~m}$. Illuminated by sunlight from the top left, this is MAHLI image 0634MH0003250050203763E01.

verse to Mt. Sharp, and in particular limited use of the robotic arm given the significant time and power resources its deployment requires. Because fulfilling MAHLI's full science investigation requires arm deployment to acquire targeted MAHLI images, MAHLI observations were largely limited to a few strategically planned stopping points along the traverse for high-priority science (Vasavada et al 2014). As a consequence, the camera was commonly used only when another science investigation or engineering need required it; of necessity, the MAHLI science investigation alone was rarely the driving force.

Even in instances when resources allow arm (and thus MAHLI) deployment, MAHLI images are often acquired of the targets that are available, rather than targets that are scientifically optimal. After Curiosity arrives at an end-of-drive position, the stability of the rover is confirmed to be sufficient for arm deployment. A usable workspace $\sim 2 \mathrm{~m}$ wide and $1 \mathrm{~m}$ deep in front of the rover is defined by constraints on positioning the $5^{\circ}$ of freedom, $2.25 \mathrm{~m}$ long robotic arm and the $50 \mathrm{~kg}, 60 \mathrm{~cm}$ diameter instrument turret on its end. Only individual targets of interest within this workspace that are characterized as safely reachable by the arm and turret are available for imaging by MAHLI. Operational time of day constraints (which are a convolution of thermal state of rover hardware at a given time of day), power for mechanism operation and heating, rover position as a function of daytime Sun position, and communications relay periods that can interrupt 


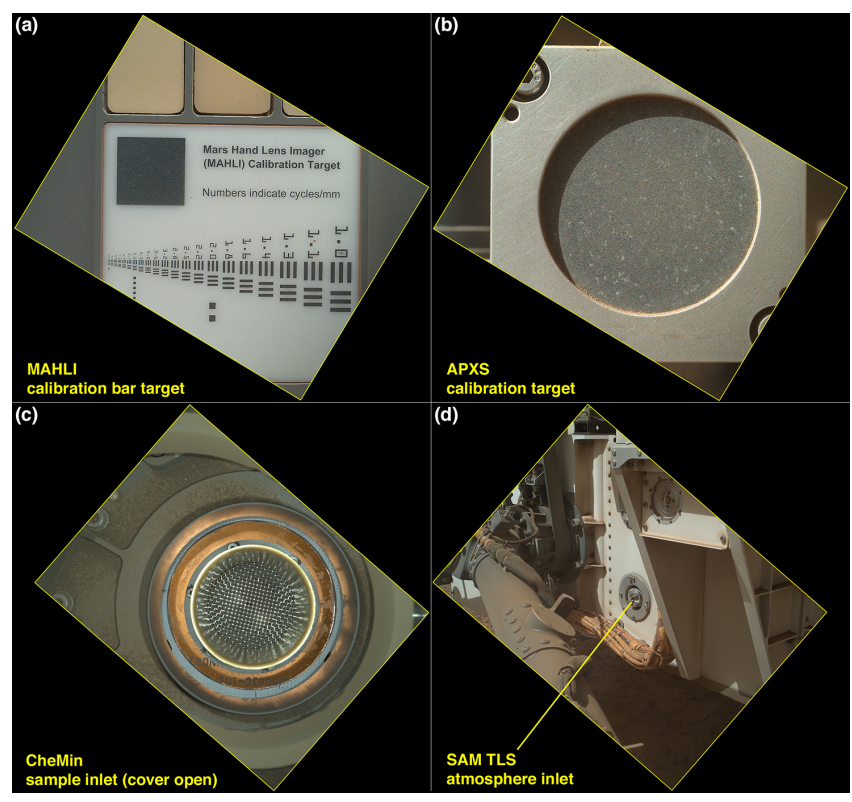

Figure 10. MAHLI images of science instrument hardware. Such images are acquired periodically, or as needed, to support instrument calibration, health, and safety. (a) Sol 989 (19 May 2015) image of a portion of the MAHLI calibration target (the full target includes the bar target seen here, as well as gray, color (RGB) and UV fluorescent swatches, stair steps, and a US cent; Edgett et al., 2012); these images are acquired on a $\sim 180$-sol cadence to monitor camera performance. Illuminated by sunlight from the top, this is MAHLI image 0989MH0004980050304442C00. (b) MAHLI image $0591 \mathrm{MH} 0003730010203137 \mathrm{C} 00$, illuminated by sunlight from the upper left on sol 591 (5 April 2014), of Curiosity's Alpha Particle X-ray Spectrometer (APXS) calibration target; these images are also obtained on a $\sim 180$-sol cadence to record dust cover (Campbell et al., 2014). (c) MAHLI view of the CheMin sample inlet (Blake et al., 2012) focused on the inlet funnel and on the $3.5 \mathrm{~cm}$ diameter millimeter mesh overlying the funnel; acquired after delivery of the sample to the CheMin instrument. Imaging of the inlet mesh and funnel is used to detect remnant material in the inlet after delivery and verifies removal of such material before the next sample delivery. Illuminated by all four of MAHLI's white light LEDs at night, this is sol 895 (12 February 2015) image 0895MH0002280000302809C00. (d) Curiosity's Sample Analysis at Mars (SAM) Tunable Laser Spectrometer (TLS) atmospheric gas inlet on the starboard side of the rover chassis. Early in the mission, MAHLI supported SAM operations by looking for evidence of disrupted sample delivery in images of both closed SAM inlet covers. Being the only camera on the rover capable of viewing it, MAHLI was used on sol 544 (16 February 2014) to seek evidence for a suspected obstruction in the SAM TLS inlet. Illuminated by sunlight from the upper left, this is MAHLI image 0544MH0003450010201448C00. Its acquisition was challenging for robotic arm positioning and thus planning for it spanned several months and included testing the operation on the full-scale testbed rover at the California Institute of Technology's Jet Propulsion Laboratory.

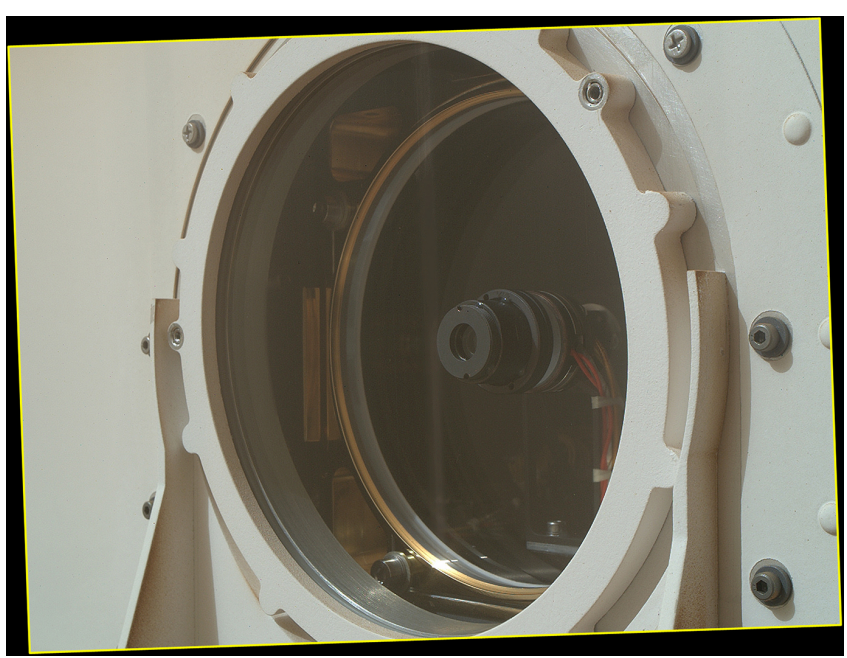

Figure 11. Example MAHLI image of the ChemCam Remote Warm Electronics Box (RWEB) window, acquired with solar illumination from the upper left on sol 808 (14 November 2014). This is onboard focus merge product 0808MH0001930000300748R00. MAHLI periodically images the ChemCam RWEB window, which contains the instrument's laser, telescopic optics and remote microscopic imager (RMI) (Maurice et al., 2012), to detect changes in dust contamination. MAHLI is also sometimes used to image the fiber optic cable that carries ChemCam signals to the spectrometers within the rover body (Wiens et al., 2012), to look for cable wear.

science data acquisition further limit the ability of MAHLI to acquire images under ideal conditions (Sect. 6.2). Expending extra sols to perfect rover positioning for arm placement of MAHLI at a given target has thus far been viewed as too resource intensive. Finally, because necessary staffing constraints limit the science team to either a drive or contact science in any given plan, the use of MAHLI is limited to available contact science planning days or requires the sacrifice of a planned rover traverse. MAHLI use has also been limited over long weekends or holidays to avoid a situation that occurred early in a campaign in the Pahrump Hills region (that campaign is explained in more detail in Sect. 6.1.2), in which the arm faulted with the MAHLI dust cover open. This situation required emergency commanding sessions to close the MAHLI cover when staff was normally not available. Because such emergency tactical procedures were a significant stress on personnel and other resources, it was decided that MAHLI use would be precluded in any command situation in which a fault could result in the dust cover remaining open over multiple sols. This further limits the observations that MAHLI can acquire.

Future missions will likely continue to rely on armmounted imagers for micron-scale grain analysis; e.g., NASA's Mars 2020 rover will carry a build-to-print MAHLI, as noted in Beegle et al. (2016), and all such imagers will have a similar limitation. One candidate solution for mitigating this limitation would be for the mission to include an 
additional camera (mast-mounted) that acquires similar highquality, high-resolution images without the need for arm motion; such images would be used to prioritize candidate contact science targets, including those for higher-resolution, arm-mounted camera viewing (e.g., MAHLI) (Yingst et al., 2014).

\subsubsection{Optimizing target selection and imaging}

In part to overcome the operational challenges of acquiring science-driven MAHLI images and increase the amount of grain-scale data acquired at a particularly science-rich site informally called Pahrump Hills (Grotzinger et al., 2015), the science team designed and executed a "walkabout-first" strategy that began around sol 750, in which the rover first explored the site with its remote sensing instruments, then used these data to down-select the best sites for more detailed, time- and resource-consuming interrogation by MAHLI and other contact instruments. This strategy, commonly used in terrestrial settings, was also used during Opportunity's examination of Whitewater Lake (Arvidson et al., 2014). This is in comparison to the linear approach commonly employed for rover fieldwork, in which the rover rarely backtracks, but instead examines all sites in the order encountered (e.g., Columbia Hills and Home Plate at the Spirit site (Arvidson et al., 2007), Endurance Crater at the Opportunity landing site (Grotzinger et al., 2005), and the Kimberley region by Curiosity (Grotzinger et al., 2014); these two methods are summarized in Yingst et al., 2015). The quantitative result of this operational strategy was 198 MAHLI science targets imaged between sols 753 and 948, compared to 478 MAHLI science targets imaged during the rest of the mission through sol 1100. Put another way, the Pahrump Hills MAHLI science image set represents $41 \%$ of all MAHLI science-driven images up to sol 1100. Qualitatively, Pahrump Hills remains the only location on Mars where more than ten vertical meters of continuous sedimentary stratigraphy have been documented and analyzed at the handlens scale ( $\mu \mathrm{m}$ to $\mathrm{mm}$ ). Additionally, this strategy enabled the team to park the rover in a favorable orientation for getting full sunlight on MAHLI targets of choice, something difficult to accomplish during normal operations where rover orientation is often determined by other factors (e.g., McBride et al., 2015).

Another scenario in which MAHLI use can be optimized is at drill sampling locations. The processes of identifying and assessing a potential drill target, drilling the target and then delivering the sample to the geochemical suite (SAM and CheMin) requires multiple sols to execute; these sols provide opportunities to identify targets of high-scientific interest (other than the drill target) and to design MAHLI observations (i.e., number and type of images, best time of day for illumination).

We recommend that for those locations studied in-depth (i.e., campaigns such as those for the areas informally known as Yellowknife Bay and Kimberley; Grotzinger et al., 2013,
2015), the walkabout-first strategy should be utilized where possible to maximize MAHLI science return. For those locations where the walkabout-first strategy is not desirable or feasible, we recommend strategically developing a robust set of science-driven criteria for MAHLI targets at each location, and a plan for reaching them (via arm motion and rover drive positioning) that is on par with, as well as in accord with, the needs of the other onboard science instrument investigations.

\subsubsection{Terminal descent plume}

Various changes in hardware configuration during the mission design period necessitated placing the MAHLI camera with its lens facing toward the rover's terminal descent plume during landing. The engines mobilized sand and dust, as witnessed by the rover's descent imager (Schieber et al., 2013), some of which was deposited on the rover hardware. While the MAHLI dust cover and camera head survived $\mathrm{Cu}$ riosity's descent to the Martian surface, the capability of the camera to image through its transparent dust cover was impaired due to the presence of a dust film that obscures the view. Further, because of this event, the first-time opening of the dust cover was delayed to add a visual inspection, using Curiosity's Mast cameras, to ensure that no deposited grains obstructed cover motion. The reduction in dust cover transparency means that the MAHLI cover must be opened in most circumstances, rather than being able to image through the cover in potentially more risky situations (for example, when a fault could result in the MAHLI cover being left open and the lens exposed to dust settling for multiple sols, or in an active dune field). Avoiding such risk has necessitated that MAHLI not be used in these situations. Future missions with similar imagers should consider avoiding an instrument accommodation in which the camera is pointed directly into the plume of dust and debris lofted by descent engines, or taking other safeguards, such as installing a one-time removable cover in addition to the existing dust cover.

\subsubsection{Stowed camera position}

Between July 2013 and September 2015, MAHLI regularly acquired an image when the robotic arm was in a stowed position (Fig. 9), after each drive. These images document a portion of the landscape, in color, although the pointing is fixed (view is to the back left of the rover). Because the camera detector (CCD) mounting position inside the instrument is rotated $210^{\circ}$ relative to the stowed position of the camera, these images are not acquired in typical "portrait" or "landscape" orientations. Serendipitously, this orientation has been found to be perfect for balancing the information content visible in the vertical and horizontal directions; sky color as a function of height can be observed, as can nearfield geologic features and mid- and far-field landmarks visible in the highest-resolution orbiter images. When the rover drove backwards to minimize wheel damage, these terminal 


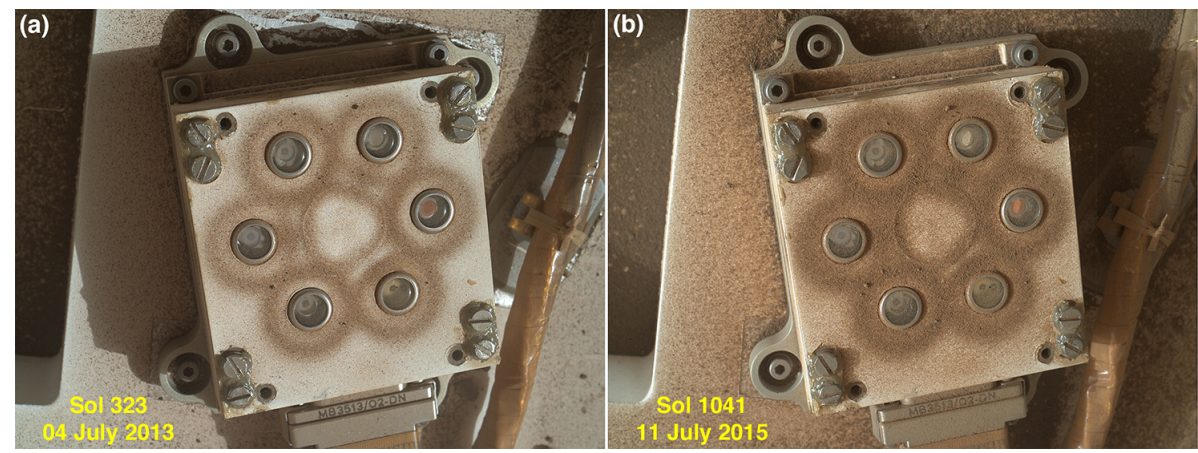

Figure 12. Comparison of dust coatings on the Rover Environmental Monitoring Station ultraviolet (REMS UV) sensor (Gómez-Elvira et al., 2012) between sols 323 and 1041. On a 60-sol cadence, MAHLI images the REMS UV sensor to monitor dust coverage over this zenithviewing sensor and its internally mounted ring-shaped magnets. In addition, on sol 526, MAHLI was employed to image the REMS meteorological boom no. 1, via a maneuver challenging to robotic arm positioning, to look for signs of damage on the boom that might have occurred during landing and led to the failure of the boom 1 wind sensor. (a) The sol 323 picture is MAHLI image 0323MH0000950010104076C00, illuminated by sunlight from the right. (b) The sol 1041 view is MAHLI image 1041MH0000950010400265C00, illuminated by sunlight from the left.

drive images often captured rover tracks and provided parting views of the terrain that yielded added geomorphological and stratigraphic context for other MSL observations.

\subsection{Imaging best practices}

\subsubsection{Dust-free surfaces}

On Earth, rain usually keeps rock outcrop surfaces clean of dust that may settle from the atmosphere. This is not the case on Mars. Dust-free surfaces are rare but yield best results in determining lithology when imaging on Mars. Areas where wind, the rover's dust removal tool (DRT; Anderson et al., 2012) or the ChemCam Laser Induced Breakdown Spectrometer (LIBS; Wiens et al., 2012) removed the surface dust provided a better science return than dust-covered surfaces (Fig. 13). A tool specifically designed to remove dust and provide contact instrument access to fresh rock surfaces, such as the descoped surface removal tool (SRT; Edgett et al., 2012) or a notional robotic rock hammer, would have been more beneficial. In lieu of such a tool, targets that have been disturbed by the rover or other hardware (e.g., broken rocks, disturbed regolith) can also provide cleaner or fresh surfaces, but opportunities to view these have been limited.

\subsubsection{Solar illumination and shadow}

Our experience shows that daytime MAHLI images of geologic materials are best acquired when the target is illuminated by sunlight, particularly with phase angles approaching $90^{\circ}$. This is because targets on Mars in full shadow tend to appear to be more orange-brown than they actually are, and the shadowing de-emphasizes vital color and textural detail (Edgett et al., 2015). That being said, it is ideal to acquire both fully sun-lit and fully shadowed views of the same target at the same scale, because both provide information that the other does not provide alone. Fully illuminated targets yield the best natural color and textural information to discern individual grains, characterize grain morphology, and identify subtle geologic features, while applying the dynamic range of the camera to a fully shadowed scene yields a scene with greater contrast, and thus a greater discrimination between subtle color differences (Fig. 14). Images acquired in partial sunlight have proven to be least useful, as both of these advantages are lessened. Specifically, such a mixed image provides less of the target in full illumination, and stretching the shadowed portion of the image is less effective as a fully shadowed image.

\subsubsection{Artificial illumination source}

When using an artificial light source, phase angle can reduce apparent depth, which in turn lessens textural heterogeneity and challenges autofocus; MAHLI's white light LEDs, which are at different positions and can operate independently (Edgett et al., 2012), can provide shadowing, lessening this problem. When imaging at night, the placement of the LEDs is adjusted to create the best image. When imaging a drill hole, for example, one set of LEDs is pointed directly down the hole. Though it did not improve image quality when used to illuminate shadowed targets during daytime or twilight, under Mars conditions, the LEDs provided effective illumination of target color and texture under nighttime conditions (Minitti et al., 2014). This is thus an important capability, as it increases the number of MAHLI imaging opportunities by permitting the acquisition of MAHLI images without delaying other activities that require daylight (e.g., driving). Thus, while the preferred illumination conditions are daytime full sunlight or shadow, the LEDs have significantly increased useful MAHLI image acquisition. 


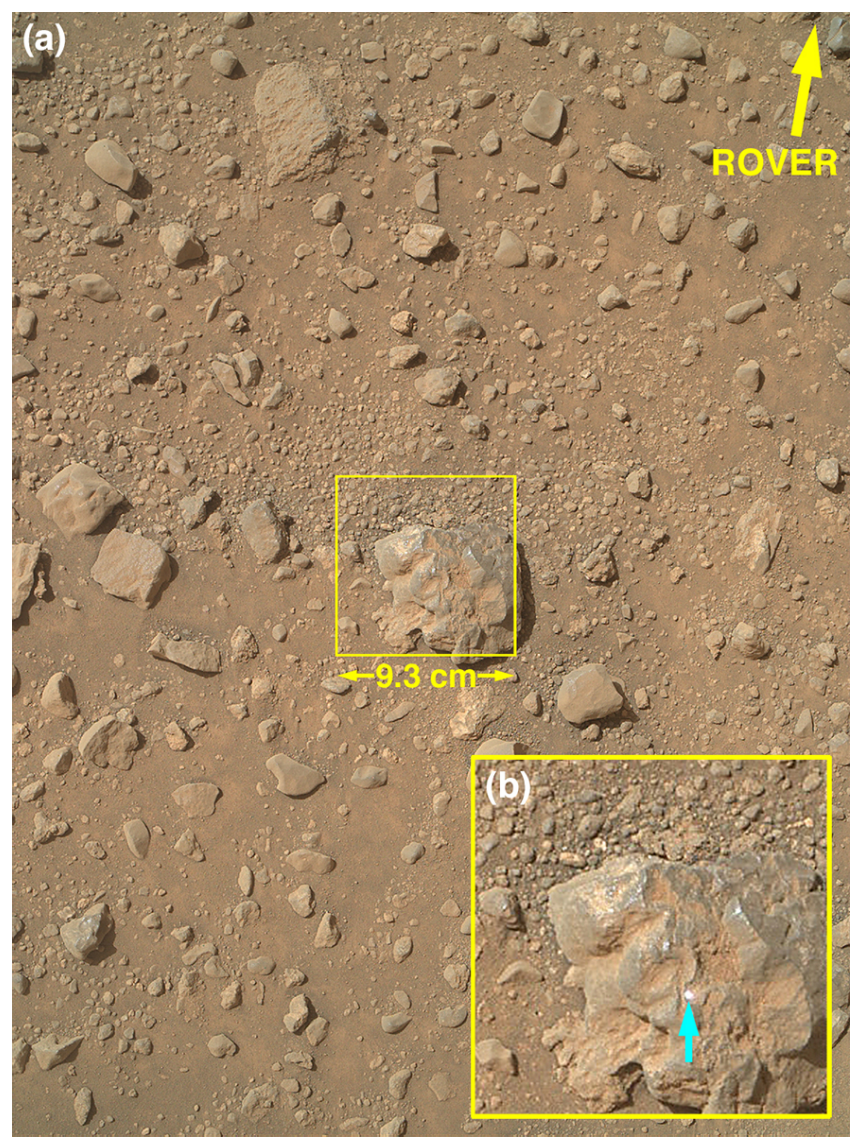

Figure 13. MAHLI images of the stone target named Nova, illuminated by sunlight from the left, acquired from $1 \mathrm{~m}$ distance on sol 687 (13 July 2014) to record, for the first time on Mars, a ChemCam LIBS investigation in action. (a) Full MAHLI field of view, covering Nova and its context, with direction to the front of the Curiosity rover indicated. The yellow box (scale, $9.3 \mathrm{~cm}$ by $9.3 \mathrm{~cm}$ ) indicates the location of sub-frames acquired using MAHLI's video capability so as to image bright flashes from ChemCam laser-induced plasma. This is MAHLI image 0687MH0004150010203989C00. (b) MAHLI video sub-frame 0687MH0004160000203993M80, expanded $2 \times$ in size; the blue arrow indicates a flash caused by LIBSgenerated plasma.

\subsubsection{Focus range and field of view}

The relatively large field of view (FOV) of MAHLI ( $38.5^{\circ}$ diagonal at infinity focus), and its ability to focus over a large range of working distances, were key capabilities that permitted crucial science-enabling rover and instrument hardware engineering observations, including imaging the rover wheels to identify and monitor damage (Fig. 6; Yingst et al., 2014); monitoring of other instruments for dust accumulation; imaging inside the laboratory inlets (e.g., SAM, CheMin) for sample cross-contamination (Fig. 10); and contributing to diagnosis or better understanding of other hardware problems (e.g., damage on REMS boom 1, ChemCam mirror dust accumulation; Fig. 11). Many of these obser- vations are now acquired at a standard cadence for routine health and safety checks of the hardware and instruments. A smaller FOV would have meant that significantly more images would be required to accomplish each of these crucial imaging activities (and thus more time and rover resources), potentially limiting the ability of the team to monitor and protect the instruments and the rover. For example, full MAHLI wheel imaging (FMWI) was originally a six-image sequence with an image manually focused on each wheel; however, the two dedicated middle wheel images were dropped after sol 574 as extraneous, because the relatively large FOV allowed all wheels to be imaged using only four images. Additionally, this FOV enables the creation of mosaics that show the entire rover in field context (Fig. 2), using 2-3x fewer images than would a similar camera with a resolution of $7-8 \mu \mathrm{m} \mathrm{pixel}^{-1}$ (and correspondingly narrower FOV). This translates to significantly less time spent on engineering and system upkeep activities, and thus more time and resources that can be devoted to science-driven activities. Future landed missions (e.g., Moon, Mars, small bodies) should consider the benefits of utilizing a high-fidelity arm-mounted camera with a large FOV and focus range to support engineering diagnostic concerns, both seen and unforeseen.

\section{Conclusions}

MAHLI has proven to be robust, efficient in operation, and flexible in the images and derivative products it yields. The combination of fine-scale resolution, RGB color, ability to focus over a large range of distances, and relatively large FOV, have provided maximum science and science-enabling return given the MSL mission architecture and constraints. Resolution down to coarse silt allows discrimination among records of potential habitable environments (mudstone vs. sandstone, for example) without greatly increasing focal length and thus mass and volume. Color has proven to be a crucial discriminator among sedimentary grains of a similar morphology, fabric or sorting, but different lithologies. This has been especially true for fine-grained rock targets, where very subtle color differences are in some cases one of the only ways to determine grain boundaries. The ability to determine the relationship between the variable focus stepper motor count and distance to the lens allows MAHLI to be used for range finding for robotic arm placement if a target has been approached once.

Finally, the MAHLI optical configuration strikes a very favorable balance between resolution and FOV, yielding accompanying benefits in mass and volume savings while enabling images from grain to rover to landscape scale.

Author contributions. R. Aileen Yingst, Kenneth S. Edgett, Marie J. McBride, Michelle E. Minitti and Rebecca M. E. Williams contributed significant analysis to the reported science results. Michael A. Ravine led the effort to build the instrument and 


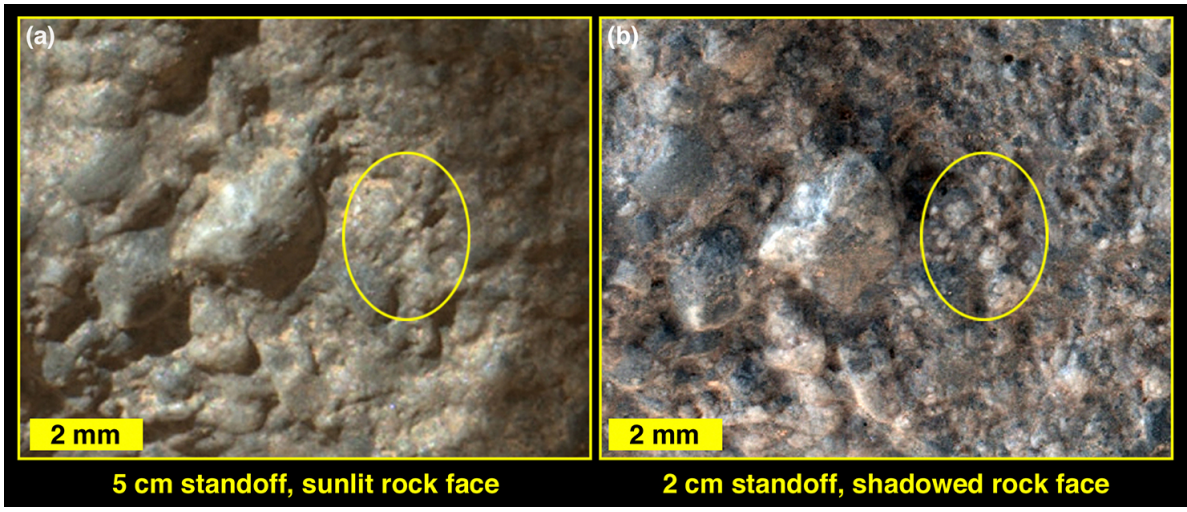

Figure 14. Information content in targets illuminated by the Sun and in full shadow can be complementary. This example is from the rock target Bardin Bluffs, imaged by MAHLI on sol 394 (14 September 2013). (a) Pebbly sandstone grains in sunlight, Sun from the upper left (shadowed by hardware at the right) in a portion of MAHLI focus merge product 0396MH0001700000104474R00. (b) Same rock surface in full shadow (cast by rover hardware) in MAHLI focus merge product 0396MH0001700000104470R00; this image has been contrast and color enhanced. Although the intrinsic spatial resolution of the two images differ, because they were acquired from different working distances, it is the difference in illumination conditions that provides complementary information about the rock. In full sunlight, the smoothness of the largest clast (just left of the yellow ellipse) results in specular reflections and grain boundaries that are difficult to identify on flatter regions of the rock. The sunlit face is ideal for discriminating grain shape and rock surface morphology. Considerably more color information is available in the shadowed image than the sunlit image. Individual white grains can be distinguished in the shadowed image (e.g., yellow ellipse), but not in the sunlit face.

Megan R. Kennedy, Gillian M. Krezoski and Michelle E. Minitti led the operations efforts, with assistance from R. Aileen Yingst and Kenneth S. Edgett. All authors contributed to the conception, development, execution and further refinement of MAHLI operational sequences. R. Aileen Yingstt prepared the manuscript with contributions from all co-authors.

Acknowledgements. We gratefully acknowledge all the individuals who have made MAHLI operations a success: the MAHLI Payload Uplink and Downlink Leads, Data Management leads, and all the engineers at JPL responsible for operating the rover arm. Additionally, we are grateful to Deirdra M. Fey for assistance with image processing and figure development. The authors also wish to thank the reviewers, whose comments improved this paper. This work was supported by the Mars Science Laboratory Program through Malin Space Science Systems contract 08-0315 to R. Aileen Yingst.

Edited by: L. Vazquez

\section{References}

Anderson, R. C., Jandura, L., Okon, A. B., Sunshine, D., Roumeliotis, C., Beegle, L. W., Hurowitz, J., Kennedy, B., Limonadi, D., McCloskey, S., Robinson, M., Seybold, C., and Brown, K.: Collecting samples in Gale Crater, Mars: an overview of the Mars Science Laboratory Sample Acquisition, Sample Processing and Handling System, Space Sci. Rev. 170, 57-75, doi:10.1007/s11214-012-9898-9, 2012.

Arvidson, R. E., Squyres, S. W., Murchie, S. L., McEwen, A. S., Athena, CRISM, and HiRISE Science Teams: Spirit's campaign in the inner basin, Columbia Hills, Gusev Crater, Lunar Planet Sci. Conf. 38th, Abs. \#1122, 2007.

Arvidson, R. E., Squyres, S. W., Bell III, J. F., Catalano, J. G., Clark, B. C., Crumpler, L. S., de Souza Jr., P. A., Fairén, A. G., Farrand, W. H., Fox, V. K., Gellert, R., Ghosh, A., Golombek, M. P., Grotzinger, J. P., Guinness, E. A., Herkenhoff, K. E., Jolliff, B. L., Knoll, A. H., Li, R., McLennan, S. M., Ming, D. W., Mittlefehldt, D. W., Moore, J. M., Morris, R. V., Murchie, S. L., Parker, T. J., Paulsen, G., Rice, J. W., Ruff, S. W., Smith, M. D., and Wolff, M. J.: Ancient aqueous environments at Endeavour crater, Mars, Science, 343, 1248097, 2014.

Beegle, L. W., Bhartia, R., DeFlores, L., Abbey, W., Carrier, B., Asher, S., Burton, A., Conrad, P., Clegg, S., Edgett, K. S., Ehlmann, B., Fries, M., Hug, W., Reid, R., Kah, L., Nealson, K., Minitti, M., Popp, J., Langenhorst, F., Orphan, V., Sobron, P., Steele, A., Tarcea, N., Wanger, G., Wiens, R., Williford, K., and Yingst, R. A.: SHERLOC: An investigation for Mars 2020, Abstract 2022, Biosignature Preservation and Detection in Mars Analog Environments, Lunar and Planetary Institute, Houston, Texas, 16-18 May 2016, Lake Tahoe, Nevada, USA, 2016.

Berger, J. A., King, P. L., Gellert, R., Campbell, J. L., Boyd, N. I., Pradler, I., Perrett, G. M., Edgett, K. S., VanBommel, S. J. V., Schmidt, M. E., and Lee, R. E. H.: MSL-APXS titanium observation tray measurements: Laboratory experiments and results fort he rocknest fines at the Curiosity field site in Gale Crater, Mars, J. Geophys. Res. 119, 1046-1060, doi:10.1002/2013JE004519, 2014.

Blake, D. F., Morris, R. V., Kocurek, G., Morrison, S. M., Downs, R. T., Bish, D., Ming, D. W., Edgett, K. S., Rubin, D., Goetz, W., Madsen, M. B., Sullivan, R., Gellert, R., Campbell, I., Treiman, A. H., McLennan, S., M., Yen, A. S., Grotzinger, J., Vaniman, D. T., Chipera, S. J., Achilles, C. N., Rampe, E. B., Sumner, D., Meslin, P.-Y., Maurice, S., Forni, O., Gasnault, O., Fisk, M., 
Schmidt, M., Mahaffy, P., Leshin, L. A., Glavin, D., Steele, A., Freissinet, C., Navarro-González, R., Yingst, R. A., Kah, L. C., Bridges, N., Lewis, K. W., Bristow, T. F., Farmer, J. D., Crisp, J. A., Stolper, E. M., Des Marais, D. J., Sarrazin, P., and the MSL Science Team: Curiosity and Gale Crater, Mars: Characterization and analysis of the Rocknest sand shadow, Science, 341, doi:10.1126/science.1239505, 2013.

Campbell, J. L., King, P. L., Burkemper, L., Berger, J. A., Gellert, R., Boyd, N. I., Perrett, G. M., Pradler, I., Thompson, L., Edgett, K. S., and Yingst, R. A.: The Mars Science Laboratory APXS calibration target: Comparison of Martian measurements with the terrestrial calibration, Nucl. Inst. Method. Phys. Res. B, 323, 4958, doi:10.1016/j.nimb.2014.01.011, 2014.

Conrad, P. G, Eigenbrode, J. L., Von der Heydt, M. O., Mogensen, C. T., Canham, J., Harpold, D. N., Johnson, J., Errigo, T., Glavin, D. P., and Mahaffy, P. R.: The Mars Science Laboratory organic check material, Space Sci. Rev., 170, 479-501, doi:10.1007/s11214-012-9893-1, 2012.

Edgett, K. S., Yingst, R. A., Ravine, M. A., Caplinger, M. A., Maki, J. N., Ghaemi, F. T., Schaffner, J. A., Bell III, J. F., Edwards, L. J., Herkenoff, K. E., Heydari, E., Kah, L. C., Lemmon, M. T., Minitti, M. E., Olson, T. S., Parker, T. J., Rowland, S. K., Schieber, J., Sullivan, R. J., Sumner, D. Y., Thomas, P. C., Jensen, E. H., Simmonds, J. J., Sengstacken, A. J., Willson, R. G., and Goetz, W.: Curiosity's Mars Hand Lens Imager (MAHLI) investigation, Space Sci. Rev., 170, 259-317, doi:10.1007/s11214012-9910-4, 2012.

Edgett, K. S., Caplinger, M. A., Maki, J. N., Ravine, M. A., Ghaemi, F. T., McNair, S., Herkenhoff, K. E., Duston, B. M., Willson, R. G., Yingst, R. A., Kennedy, M. R., Minitti, M. E., Sengstacken, A. J., Supulver, K. D., Lipkaman, L. J., Krezoski, G. M., McBride, M. J., Jones, T. L., Nixon, B. E., Van Beek, J. K., Krysak, D. J., and Kirk, R. A.: Curiosity's robotic arm-mounted Mars Hand Lens Imager (MAHLI): Characterization and calibration status, MSL MAHLI Technical Report 0001, version 2 (5 October 2015). doi:10.13140/RG.2.1.3798.5447, 2015.

Gómez-Elvira, J., Armiens, C., Castañer, L., Domínguez, M., Genzer, M., Gómez, F., Haberle, R., Harri, A.-M., Jiménez, V., Kahanpää, H., Kowalski, L., Lepinette, A., Martín, J., MartínezFrías, J., McEwan, I., Mora, L., Moreno, J., Navarro, S., de Pablo, M. A., Peinado, V., Peña, A., Polkko, J., Ramos, M., Renno, N. O., Ricart, J., Richardson, M., Rodríguez-Manfredi, J., Romeral, J., Sebastián, E., Serrano, J., de la Torre Juárez, M., Torres, J., Torrero, F., Urquí, R., Vázquez, L., Velasco, T., Verdasca, J., Zorzano, M.-P., and Martín-Torres, J.: REMS: The environmental sensor suite for the Mars Science Laboratory rover, Space Sci. Rev., 170, 583-640, doi:10.1007/s11214-012-9921-1, 2012.

Grotzinger, J. P., Arvidson, R. E., Bell, J. F., Calvin, W., Clark, B. C., Fike, D. A.,Golombek, M., Greeley, R., Haldemann, A., Herkenhoff, K. E.,Jolliff, B. L., Knoll, A. H., Malin, M., McLennan, S. M., Parker, T., Soderblom, L., Sohl-Dickstein, J. N., Squyres, S. W., Tosca, N. J., and Watters, W. A.: Stratigraphy and sedimentology of a dry to wet eolian depositional system, Burns formation, Meridiani Planum, Mars, Earth Planet. Sci. Lett., 240, 11-72, 2005.

Grotzinger, J. P., Crisp, J., Vasavada, A. R., Anderson, R. C., Baker, C. J., Barry, R., Blake, D. F., Conrad, P., Edgett, K. S., Ferdowski, B., Gellert, R., Gilbert, J. B., Golombek, M., Gómez-Elvira, J., Hassler, D. M., Jandura, L., Litvak, M., Mahaffy, P., Maki, J.,
Meyer, M., Malin, M. C., Mitrofanov, I., Simmonds, J. J., Vaniman, D., Welch, R. V., and Wiens, R. C.: Mars Science Laboratory mission and science investigation, Space Sci. Rev., 170, 5-56, doi:10.1007/s11214-012-9892-2, 2012.

Grotzinger, J. P., Sumner, D. Y., Kah, L. C., Stack, K., Gupta, S., Edgar, L., Rubin, D., Lewis, K., Schieber, J., Mangold, N., Milliken, R., Conrad, P. G., Des Marais, D., Farmer, J., Siebach, K., Calef III, F., Hurowitz, J., McLennan, S. M., Ming, D., Vaniman, D., Crisp, J., Vasavada, A., Edgett, K. S., Malin, M., Blake, D., Gellert, R., Mahaffy, P., Wiens, R. C., Maurice, S., Grant, J. A., Wilson, S., Anderson, R. C., Beegle, L., Arvidson, R., Hallet, B., Sletten, R. S., Rice, M., Bell, J., III, Griffes, J., Ehlmann, B., Anderson, R. B., Bristow, T. F., Dietrice, W. E., Dromart, G., Eigenbrode, J., Fraeman, A., Hardgrove, C., Herkenhoff, K., Jandura, L., Kocurek, G., Lee, S., Leshin, L. A., Leveille, R., Limonadi, D., Maki, J., McCloskey, S., Meyer, M., Minitti, M., Newsom, H., Oehler, D., Okon, A., Palucis, M., Parker, T., Rowland, S., Schmidt, M., Squyres, S., Steele, A., Stolper, E., Summons, R., Treiman, A., Williams, R., Yingst, A., and the MSL Science Team: A habitable fluvio-lacustrine environment at Yellowknife Bay, Gale Crater, Mars, Science, 343, 6169, doi:10.1126/science.1242777, 2013.

Grotzinger, J. P., Sumner, D. Y., Kah, L. C., Stack, K., Gupta, S., Edgar, L., Rubin, D., Lewis, K., Schieber, J., Mangold, N., Milliken, R., Conrad, P. G., DesMarais, D., Farmer, J., Siebach, K., Calef III, F., Hurowitz, J., McLennan, S. M., Ming, D., Vaniman, D., Crisp, J., Vasavada, A., Edgett, K. S., Malin, M., Blake, D., Gellert, R., Mahaffy, P., Wiens, R. C., Maurice, S., Grant, J. A., Wilson, S., Anderson, R. C., Beegle, L., Arvidson, R., Hallet, B., Sletten, R. S., Rice, M., Bell III, J., Griffes, J., Ehlmann, B., Anderson, R. B., Bristow, T. F., Dietrich, W. E., Dromart, G., Eigenbrode, J., Fraeman, A., Hardgrove, C., Herkenhoff, K., Jandura, L., Kocurek, G., Lee, S., Leshin, L. A., Leveille, R., Limonadi, D., Maki, J., McCloskey, S., Meyer, M., Minitti, M., Newsom, H., Oehler, D., Okon, A., Palucis, M., Parker, T., Rowland, S., Schmidt, M., Squyres, S., Steele, A., Stolper, E., Summons, R., Treiman, A., Williams, R., Yingst, A., and MSL Science Team: A habitable fluvio-lacustrine environment at Yellowknife Bay, Gale Crater, Mars, Science, 343, 1242777 , doi:10.1126/science.1242777, 2014.

Grotzinger, J. P., Gupta, S., Grotzinger, J. P., Gupta, S., Malin, M. C., Rubin, D. M., Schieber, J., Siebach, K., Sumner, D. Y., Stack, K. M., Vasavada, A. R., Arvidson, R. E., Calef III, F., Edgar, L., Fischer, W. F., Grant, J. A., Griffes, J., Kah, L. C., Lamb, M. P., Lewis, K. W., Mangold, N., Minitti, M. E., Palucis, M., Rice, M., Williams, R. M. E., Yingst, R. A., Blake, D., Blaney, D., Conrad, P., Crisp, J., Dietrich, W. E., Dromart, G., Edgett, K. S., Ewing, R. C., Gellert, R., Hurowitz, J. A., Kocurek, G., Mahaffy, P., McBride, M. J., McLennan, S. M., Mischna, M., Ming, D., Milliken, R., Newsom, H., Oehler, D., Parker, T. J., Vaniman, D., Wiens, R. C., and Wilson, S. A.: Deposition, exhumation, and paleoclimate of an ancient lake deposit, Gale crater, Mars, Science, 350, 6257, doi:10.1126/science.aac7575, 2015.

Maurice, S., Wiens, R. C., Saccoccio, M., Barraclough, B., Gasnault, O., Forni, O., Mangold, N., Baratoux, D., Bender, S., Berger, G., Bernardin, J., Berthé, M., Bridges, N., Blaney, D., Bouyé, M., Caïs, P., Clark, B., Clegg, S., Cousin, A., Cremers, D., Cros, A., DeFlores, L., Derycke, C., Dingler, B., Dromart, G., Dubois, B., Dupieux, M., Durand, E., d’Uston, L., Fabre, C., 
Faure, B., Gaboriaud, A., Gharsa, T., Herkenhoff, K., Kan, E., Kirkland, L., Kouach, D., Lacour, J.-L., Langevin, Y., Lasue, J., Le Mouélic, S., Lescure, M., Lewin, E., Limonadi, D., Manhès, G., Mauchien, P., McKay, C., Meslin, P.-Y., Michel, Y., Miller, E., Newsom, H. E., Orttner, G., Paillet, A., Parès, L., Parot, Y., Pérez, R., Pinet, P., Poitrasson, F., Quertier, B., Sallé, B., Sotin, C., Sautter, V., Séran, H., Simmonds, J. J., Sirven, J.-B., Stiglich, R., Striebig, N., Thocaven, J.-J., Toplis, M. J., and Vaniman, D.: The ChemCam instrument suite on the Mars Science Laboratory (MSL) rover: Science objectives and mast unit description, Space Sci Rev 170, 95-166. doi:10.1007/s11214-012-9912-2, 2012.

McBride, M. J., Minitti, M. E., Stack, K. M., Yingst, R. A., Edgett, K. S., Goetz, W., Herkenhoff, K. E., Heydari, E., Kah, L. C., Rowland, S. K., Schieber, J., Harker, D., Kennedy, M. R., Krezoski, G. M., Lipkaman, L., Nixon, B., and Van Beek, J.: Mars Hand Lens Imager (MAHLI) observations at the Pahrump Hills field site, Gale crater, 46th Lunar Planet. Science Conf., Houston, Texas, Abs. 2885, 2015.

Minitti, M. E., Kah, L. C., Yingst, R. A., Edgett, K. S., Anderson, R. C., Beegle, L. W., Carsten, J. L., Deen, R. G., Goetz, W., Hardgrove, C., Harker, D. E., Herkenhovv, K. E., Hurowitz, J. A., Jandura, L., Kennedy, M. R., Kocurek, G., Krezoski, G. M., Kuhn, S. R., Limonadi, D., Lipkaman, L., Madsen, M. B., Olson, T. S., Robinson, M. L., Rowland, S. K., Rubin, D. M., Seybold, C., Schieber, J., Schmidt, M., Sumner, D. Y., Tompkins, V. V., Van Beek, J. K., and Van Beek, T.: MAHLI at the Rocknest sand shadow: Science and science-enabling activities, J. Geophys. Res., 118, 2338-2360, doi:10.1002/2013JE004426, 2013.

Minitti, M. E., Edgett, K. S., Yingst, R. A., Conrad, P. G., Fisk, M., Hardgrove, C. J., Herkenhoff, K. E., Kah, L. C., Kennedy, M. R., Krezoski, G. M., Lemmon, M. T., Lipkaman, L., Kuhn, S. R., Robinson, M. L., Tompkins, V. V., Treiman, A., and Williford, K. H.: MAHLI after dark: Nighttime Mars Hand Lens Imager observations under LED illumination, Lunar Planet. Sci. Conf., 45th, Houston, Texas, Abs. 2029, 2014.

Robinson, M., Collins, C., Leger, P., Kim, W., Carsten, J., and Tompkins, V.: Test and validation of the Mars Science Laboratory robotic arm, 8th International Conference on System of Systems Engineering (SoSE), 8th conference, Maui, HI, 184-189, doi:10.1109/SYSoSE.2013.6575264, 2013.

Schieber, J., Malin, M. C., Olson, T., Calef, F., Comeaux, K., and the MSL Science Team: The final 2 1/2 minutes of terror - What we learned about the MSL landing from the images taken by the MARDI descent imager, 44th Lunar Planet. Sci. Conf., Houston, Texas, Abs. 1260, 2013.

Stack, K. M., Grotzinger, J. P., Kah, L. C., Schmidt, M. E., Mangold, N., Edgett, K. S., Sumner, D. Y., Siebach, K. L., Nachon, M., Lee, R., Blaney, D. L., Deflores, L. P., Edgar, L. A., Fairén, A. G., Leshin, L. A., Maurice, S., Oehler, D. Z., Rice, M. S., and Wiens, R. C.: Diagenetic origin of nodules in the Sheepbed member, Yellowknife Bay formation, Gale crater, Mars, J. Geophys. Res,. 119, 1635-1664, doi:10.1002/2014JE004617, 2014.

Sullivan, R., Bridges, N., Herkenhoff, K., Hamilton, V., and Rubin, D.: Transverse aeolian ridges (TARs) as megaripples: Rover encounters at Meridiani Planum, Gusev, and Gale, 8th Internat. Conf. Mars, Pasadena, CA, Abs. 1424, 2014.
Summons, R. E., Amend, J. P., Bish, D., Buick, R., Cody, G. D., Des Marais, D. J., Dromart, G., Eigenbrode, J. L., Knoll, A. H., and Sumner, D. Y.: Preservation of martian organic and environmental records: final report of the Mars biosignature working group, Astrobiology, 2, 157-181, doi:10.1089/ast.2010.0506, 2011.

Wentworth, C. K.: A scale of grade and class terms for clastic sediments, J. Geol., 30, 377-392, doi:10.1086/622910, 1922.

Wiens, R. C., Maurice, S., Barraclough, B., Saccoccio, M., Barkley, W. C., Bell III, J. F., Bender, S., Bernardin, J., Blaney, D., Blank, J., Bouyé, M., Bridges, N., Bultman, N., Caïs, P., Clanton, R. C., Blark, B., Clegg, S., Cousin, A., Cremers, D., Cros, A., DeFlores, L., Delapp, D., Dingler, R., D’Uston, C., Dyar, M. D., Elliott, T., Enemark, D., Fabre, C. Flores, M., Forni, O., Gasnault, O., Hale, T., Hays, C., Herkenhoff, K., Kann, E., Kirkland, L., Kouach, D., Landis, D., Langevin, Y., Lanza, N., LaRocca, F., Lasue, J., Latino, J., Limonadi, D., Lindensmith, C., Little, C., Mangold, N., Manhes, G., Mauchien, P., McKay, C., Miller, E., Mooney, J., Morris, R. V., Morrison, L., Nelson, T., Newsom, H., Ollila, A., Ott, M., Pares, L., Perez, R., Poitrasson, F., Provost, C., Reiter, J. W., Roberts, T., Romero, F., Sautter, V., Salazar, S., Simmonds, J. J., Stiglich, R., Storms, S., Striebig, N., Thocaven, J., Trujillo, T., Ulibarri, M., Vaniman, D., Warner, N., Waterbury, R., Whitaker, R., Witt, J., and Wong-Swanson, B.: The ChemCam instrument suite on the Mars Science Laboratory (MSL) rover: Body unit and combined system tests, Space Sci Rev., 170, 167-227, doi:10.1007/s11214-012-9902-4, 2012.

Vasavada, A. R., Grotzinger, J. P., Arvidson, R. E., Calef, F. J., Crisp, J. A., Gupta, S., Hurowitz, J., Mangold, N., Maurice, S., Schmidt, M. E., Wiens, R. C., Williams, R. M. E., and Yingst, R. A.: Overview of the Mars Science Laboratory mission: Bradbury Landing to Yellowknife Bay and beyond, J. Geophys. Res. Planet., 119, 1134-1161, doi:10.1002/2014JE004622, 2014.

Williams, R. M. E., Grotzinger, J. P., Dietrich, W. E., Gupta, S., Sumner, D. Y., Wiens, R. C., Mangold, N., Malin, M. C., Edgett, K. S., Maurice, S., Forni, O., Gasnault, O., Ollila, A., Newsom, H. E., Dromart, G., Palucis, M. C., Yingst, R. A., Anderson, R. B., Herkenhoff, K. E., Le Mouélic, S., Goetz, W., Madsen, M. B., Koefoed, A., Jensen, J. K., Bridges, J. C., Schwenzer, S. P., Lewis, K. W., Stack, K. M., Rubin, D., Kah, L. C., Bell III, J. F., Farmer, J. D., Sullivan, R., Van Beek, T., Blaney, D. L., Pariser, O., Deen, R. G., and MSL Science Team: Martian fluvial conglomerates at Gale Crater, Science, 340, 1068-1072, doi:10.1126/science.1237317, 2013.

Yingst, R. A., Hamilton, V. E., Arvidson, R., Calef, F., Grotzinger, J., Lewis, K., and Williams, R. M. E.: Terrain assessment in Gale Crater from sol 0-500 using orbital thermal inertia and in situ visible data, Geol. Soc. Am. Abs., \#202-8, 2014.

Yingst, R. A., Berger, J. A., Cohen, B. A., Hynek, B. M., and Schmidt, M. E.: A test of two field methods: Determining best practices in reconnoitering sites for habitability potential using a semi-autonomous rover, Lunar Planet. Sci. Conf., Houston, Texas, Abs. \#1640, 2015. 